EXTENDED REPORT

\title{
Development of organised conjunctival leucocyte aggregates after corneal transplantation in rats
}

\author{
S Banerjee, F C Figueiredo, D L Easty, A D Dick, S M Nicholls
}

Br J Ophthalmol 2003;87:1515-1522

See end of article for authors' affiliations

Correspondence to:

Dr Sanjiv Banerjee, Bristol

Eye Hospital, Lower

Maudlin Street, Bristol BS1

2LX, UK; s.banerjee@

bristol.ac.uk

Accepted for publication 11 March 2003

\begin{abstract}
Aim: To investigate the development of lymphoid aggregates in the conjunctiva after corneal transplantation in rats.

Methods: LEW or PVG strain corneas were transplanted orthotopically to PVG rats. Cornea and conjunctiva were examined clinically for up to 42 days. Eyes were removed with attached conjunctiva on days 10 and 15 after transplantation (before and during rejection), together with normal eyes, fixed, paraffin embedded, and examined immunohistochemically.

Results: Clinically, the temporal half of the upper palpebral conjunctiva of recipients of 10/19 allografts and $1 / 10$ isografts developed pronounced swelling, correlating with inflammation and rejection. Histologically, the swelling comprised leucocytic aggregates with an altered overlying epithelium. Aggregates contained granulocytes, macrophages, and cells expressing major histocompatibility complex $(\mathrm{MHC})$ class II, CD4, and CD8, all more numerous in allograft associated conjunctiva. Class $\mathrm{II}^{+}$cells were more abundant at the surface, whereas macrophages and T cells were more numerous in the deeper stroma. There were few B cells. There was greater CD54 expression by vascular endothelium in allograft associated aggregates. Cells expressing TNF $\alpha$ and IFN $\gamma$ but not IL1 $\beta$ were present in stromal and superficial areas.

Conclusions: Corneal transplantation in rats induces the development of organised conjunctival leucocytic aggregates in a fixed location that are significantly more pronounced in recipients of allografts compared with isografts and show characteristics of a Thl type immune response. These aggregates have characteristics of conjunctiva associated lymphoid tissue and may be sites of presentation of graft antigens and lymphocyte proliferation at the ocular surface.
\end{abstract}

T he conjunctiva, like other mucosal surfaces, is vulnerable to penetration by pathogenic micro-organisms and must be protected by immune mechanisms which do not elicit inappropriate responses to innocuous antigens such as commensal bacteria and allergens. The archetypical mucosal lymphoid tissue is gut associated lymphoid tissue (GALT) containing diffusely distributed leucocytes and Peyer's patches, consisting of $\mathrm{CD}^{+}$and $\mathrm{CD}^{+} \mathrm{T}$ cells, high endothelial venules (HEV), ${ }^{12}$ and B cell follicles, ${ }^{1}$ and which secrete IgA directly into the intestinal lumen. ${ }^{3}$ A further morphological feature that defines GALT and bronchus associated lymphoid tissue (BALT) is the M cell, which facilitates antigen uptake. Antigen presentation through the mucosa can generate either a tolerogenic or an immunogenic T cell response. ${ }^{1}$ Whether or not tolerance develops depends on antigen type and dose, ${ }^{45}$ leucocyte populations, ${ }^{6}$ and environment of the local draining lymph nodes..$^{58}$ The term mucosa associated lymphoid tissue (MALT) includes any mucosa with lymphoreticular tissue, ${ }^{9}$ despite the fact that MALT at different sites exhibits both organ specific and species specific variations, particularly with respect to antigen handling. ${ }^{10}{ }^{11}$

The conjunctiva has conjunctiva associated lymphoid tissue (CALT) ${ }^{12}{ }^{13}$ which has been described variously as (i) a diffuse presence of lymphocytes within conjunctiva and subconjunctival tissue, ${ }^{14}$ and (ii) leucocytes within an organised follicle-like structure. ${ }^{13}$ It resembles the respiratory tract in being exposed to airborne proteins and might be expected to elicit downregulatory responses. Indeed, although there are variations in morphology between species, ${ }^{15}$ there is functional resemblance to gut mucosa in that tolerance can be induced in response to antigen delivery to the conjunctival surface. ${ }^{16}{ }^{17}$ However, others have reported a lack of antigen uptake by normal conjunctiva. ${ }^{18}$ The presence of $\mathrm{B}$ cell follicles has been suggested as a prerequisite to induction of tolerance, ${ }^{19}$ although in rats and mice these are not normally present in conjunctiva ${ }^{15} 20$ and are not universally present in normal human conjunctiva. ${ }^{14} 21$ Similarly, neither M cells nor any other means of transport of antigen across the human conjunctiva has been found..$^{22}$ Lymphoid aggregates increase in number in GALT and may differ in composition in response to antigenic load. In sites outside the gut they are not constitutively present. ${ }^{10}$ In rats, where organised CALT is not normally present, the generation of an organised follicular lymphoid aggregate may confer a structure that is (i) comparable to those present at other mucosal sites, and (ii) a means of modulating local and systemic immune responses only when inflammation is present. Therefore, the question arises whether during the inflammatory stimulus of corneal transplantation such a structure is generated. We describe here the generation of a leucocytic aggregate in the conjunctiva with a predominantly proinflammatory Thl infiltrate in a rat model of corneal allograft rejection. ${ }^{23}$

\section{MATERIALS AND METHODS}

Animals

Specific pathogen free, 8-10 week old female PVG $\left(\mathrm{RTI}^{\mathrm{C}}\right)$ and LEW $\left(\mathrm{RTl}^{\mathrm{l}}\right)$ inbred rats (Harlan, Bicester, UK) were used for corneal transplantation. All animals were cared for in accordance with the ARVO statement for the use of animals in ophthalmic and vision research.

\section{Corneal transplantation and clinical examination}

Penetrating keratoplasties were performed as previously described. ${ }^{23}$ PVG strain recipients were anaesthetised by separate intramuscular injection of Hypnorm $(0.7 \mathrm{ml} / \mathrm{kg}$; 
fentanyl fluanisone, Jansen, Oxford, UK) and Valium (2.5 mg/kg diazepam, Roche, Welwyn Garden City, UK) and received Lewis or PVG strain grafts. Donor corneas were excised using a $3.5 \mathrm{~mm}$ trephine. The recipient graft bed was created using a $3 \mathrm{~mm}$ trephine. Corneas were sutured with 12 interrupted 11/0 Nylon sutures. Animals received 1\% topical chloromycetin ointment (Forley Ltd, Ireland) immediately after surgery and on alternate day thereafter with $1 \%$ atropine sulphate eye drops (Schering-Plough, Welwyn Garden City, UK) for 2 weeks. Corneal appearance was scored by slit lamp biomicroscopy on alternate days. Corneal allograft rejection was defined as previously described..$^{23}$ By everting the eyelid, conjunctivas on the grafted and normal side was scored for swelling, hyperaemia, loss of pigmentation, and size of the area involved. Changes were scored as detailed in Table 1.

\section{Tissue fixation, embedding, and sectioning}

On days 10 and 15 after transplantation animals were killed and eyes were enucleated, conserving the bulbar and palpebral conjunctiva as far as the lid margin. Tissues were fixed and processed as described previously. ${ }^{24}$ Briefly, globes were then injected with periodate-lysine-paraformaldehyde (PLP, 0.25\% paraformaldehyde) and further fixed in PLP overnight at $4^{\circ} \mathrm{C}$. The eyes with their adnexae were bisected sagitally, washed in phosphate buffered saline (PBS) and then rapidly dehydrated in graded ethanols and Histoclear (National Diagnostics, Hull, UK). They were infiltrated under vacuum with low temperature paraffin wax at $54^{\circ} \mathrm{C}$ and embedded, with the two halves of the eye central side downwards in the same block, so that sections of cornea with attached conjunctiva were obtained from the centre outwards. Sections of $6 \mu \mathrm{m}$ were cut, placed three per slide, dried at $37^{\circ} \mathrm{C}$ overnight, and stored at $-20^{\circ} \mathrm{C}$.

\section{Immunohistology}

Immunoperoxidase staining was performed as previously described $^{24} 25$ using the antibodies listed in Table 2. To identify cytokine expressing cells, an immunofluorescence double staining technique was used. For this, tissue sections were blocked with $4 \%$ normal serum of the host species of the first secondary antibody for 1 hour in a moist chamber. Then sections were incubated overnight at $4{ }^{\circ} \mathrm{C}$ with the first primary antibody (cell surface marker) or isotype control antibody, followed by incubation at room temperature for 1 hour with FITC conjugated secondary antibody (diluted 1:50) (Jackson ImmunoResearch, PA, USA). Intervening washes were done with PBS, $0.1 \%$ saponin. Sections were then blocked with $4 \%$ normal serum of the host of the second secondary antibody and incubated overnight with anticytokine antibody or isotype control antibody, followed by biotinylated secondary antibody diluted 1:100 (Jackson ImmunoResearch) for 1 hour. Both secondary antibodies were purchased pre-absorbed against immunoglobulins of the host species of the other primary and secondary antibodies and against rat immunoglobulin. Finally, sections were incubated with TRITC conjugated streptavidin diluted 1:200 (Jackson ImmunoResearch, PA, USA) and mounted in Vectashield (Vector, Burlingame, CA, USA). Positive control sections of spleen were included in each staining run.

\section{Quantification of cells}

Sections stained by the immunoperoxide method were examined and stained cells were quantified at $\times 400$ magnification using a Leica Leitz DMRB upright light microscope and an image analysis system (Quantimet; Leica, Cambridge, UK). Stained cells from eyes with lymphoid aggregates were counted in the deeper stromal area and in the superficial area of the aggregates where epithelium was absent (Fig 1). Immunofluorescent stained tissue was examined either on a Leica DMIRBE inverted epifluorescence microscope, confocal images being obtained using a TCS NT confocal laser scanning unit, or with Improvision Openlab software with digital controlled CCD camera. The confocal system was equipped with an argon krypton laser (488, 568, $647 \mathrm{~nm}$ lines) and argon ultraviolet laser ( 351 and $364 \mathrm{~nm}$ ), providing three channels for simultaneous detection of fluorescence/reflectance.

The difference between allograft and isograft conjunctiva was assessed by comparing the incidence of aggregates with a score of 3 (the score which correlates with histologically identifiable aggregate) and above at day 10 and 15 after transplantation. A Fisher's exact test was used. SPSS for Windows software was used for statistical analysis. A p value of $<0.05$ was considered significant.

\section{Experimental protocol}

We previously established that graft rejection in this model occurred in all animals between days 10 and 15 after transplantation (median day 13). ${ }^{23}$ A first group of animals was examined clinically before transplantation and on days $3,6,10$, and 15 after transplantation and scored the development of leucocytic aggregates in relation to rejection. A second group was examined on days 18, 21, 25, 30, and 42 to determine whether these aggregates persisted. A further group of animals was killed after transplantation when conjunctival swelling was found to be clinically most prominent-that is, on days 10 (early stage of rejection) and 15 (rejection under way in all animals). The groups of animals used for immunostaining are shown in Table 3. Conjunctivae of unoperated rats were also examined. Every 13th slide was stained by haematoxylin and eosin (H\&E) to verify the location of the aggregates in relation to the cornea. Intervening sections were then stained in sequence with the appropriate monoclonal antibody or negative control antibody and cell infiltrate was quantified in specimens with the leucocytic aggregates. We were unsuccessful in assessing expression of IL-2, IL-4, IL-10, and TGF $\beta$ in control tissue expected to contain these cytokines and therefore concluded that the antibodies available were not suitable for immunohistology. NK cell numbers were estimated as a percentage of infiltrating cells.

\begin{tabular}{|c|c|c|c|c|}
\hline Score & 1 & 2 & 3 & 4 \\
\hline Conjunctival swelling* & Mild & $\begin{array}{l}\text { Moderate with diffuse } \\
\text { margin }\end{array}$ & $\begin{array}{l}\text { Moderate with discrete } \\
\text { margin }\end{array}$ & $\begin{array}{l}\text { Severe with } \\
\text { overhanging edge }\end{array}$ \\
\hline $\begin{array}{l}\text { Pigmentation over } \\
\text { swelling }\end{array}$ & $\begin{array}{l}\text { Loss of some } \\
\text { pigment }\end{array}$ & Loss of some pigment & Depigmented & Depigmented \\
\hline Hyperaemia & None & Generalised & Localised petechiae & $\begin{array}{l}\text { Localised patchy, } \\
\text { haemorrhagic } \\
\text { appearance }\end{array}$ \\
\hline
\end{tabular}


Table 2 Antibodies used in histological staining

\begin{tabular}{lll}
\hline Clone (antigen) & Specificity & Source \\
\hline W3/25 (CD4) & T helper cells and monocytes & Harlan Seralab, Loughborough, UK \\
OX8 (CD8 $\alpha)$ & Cytotoxic T lymphocytes and dendritic cells & Harlan Seralab \\
OX33 (CD45RA) & B cells & Harlan Seralab \\
ED2 & Tissue macrophage & Serotec, Oxford, UK \\
HIS48 & Granulocytes & Pharmingen, Oxford, UK \\
OX39 (CD25) & IL2 receptor & Harlan Seralab \\
WT.3 (CD18) & LFA1- $\beta$ & Harlan Seralab \\
IA29 (CD54) & ICAM-1 & Harlan Seralab \\
OX34 (CD2) & T cells and dendritic cells & Harlan Seralab \\
OX6 & MHC class II & Serotec \\
$10 / 78$ (CD161) & NK cells & Serotec \\
SILK6 & IL1 $\beta$ & Serotec \\
Rabbit Polyclonal & TNF $\alpha$ & Serotec \\
RP64 & IFN $\gamma$ & Harlan Seralab \\
$6 B 10$ & Cytokeratin peptide 4 & Sigma, St Louis, MI, USA \\
LL002 & Cytokeratin peptide 14 & Biogenex, San Ramon, CA, USA \\
C-11 & Anti-pan cytokeratin & Sigma \\
\hline & &
\end{tabular}

\section{RESULTS \\ Morphology of conjunctiva in unoperated and transplanted eyes}

Clinical examination of conjunctiva of unoperated animals $(n=6)$ showed normal blood vessels, scattered pigment and a uniform surface without swelling (Fig 2A). Histologically the epithelium was intact with melanocytes and without lymphoid aggregates. Conjunctival blood vessels exhibited a flattened endothelium and were most prominent adjacent to the limbus. Immunohistochemical staining showed a few scattered $\mathrm{CD}^{+}$and $\mathrm{CD} 8 \alpha^{+} \mathrm{T}$ cells, class $\mathrm{II}^{+}$cells, and $\mathrm{ED}^{+}$ macrophages (Fig 2B) and occasional granulocytes. CD $4^{+}$ cells were both dendritic and round. Intraepithelial $\mathrm{CD} 8 \alpha^{+}$ cells were seen (Fig 2C).

Clinical examination 3 days post-transplantation, revealed swelling and hyperaemia of the upper temporal palpebral conjunctiva. This increased until day 10 to form a discrete oval swelling lacking pigment with numerous capillaries (Fig 2D), which then subsided in most isografts by day 15 (Fig 3), but persisted until day 25 in some allografts, after which the only residual change was lack of pigment. Clinical conjunctival scores were compared in all rats examined on days 10 and 15 . These scores were 3 or greater in conjunctivas of 10/19 allografts recipients and 1/10 isograft recipients on day 15 after transplantation $(p=0.03)$, but there was no

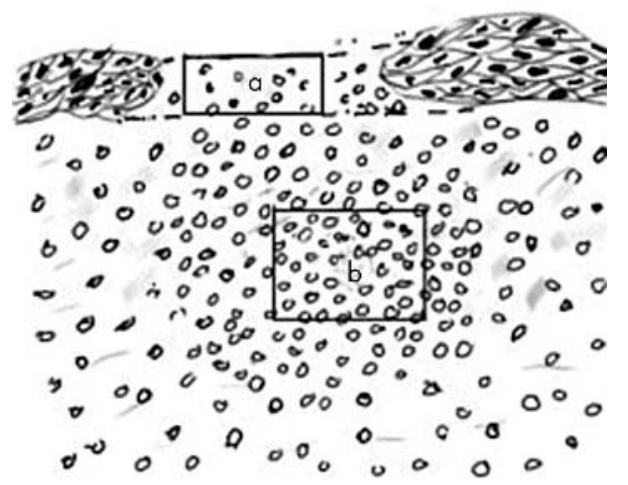

Figure 1 Schematic diagram of superficial (a) and stromal (b) areas counted for cell infiltrate. " $a$ " had the same width as " $b$ ", but its height varied according to the thickness of the adjacent epithelium. Counts were adjusted to number per $0.04 \mathrm{~mm}^{2}$ (the size of the image analysis screen). " $b$ " was $0.04 \mathrm{~mm}^{2}$ and located in the area of maximum infiltrate. significant difference on day $10(p=0.1)$. In four allograft and four isograft recipients we performed a second corneal transplant 42 days after the first transplant. Conjunctival swelling developed more rapidly (within 3 days) and with clinical scores greater than 3 only in animals (two allografts and one isograft) where swelling of at least score 3 was induced by the first transplantation.

Histologically, conjunctivas of transplanted eyes had a diffuse mixed cell infiltrate. Fully developed leucocytic aggregates, corresponding to a clinical score of 3, were identified by the following features: subepithelial leucocytes in a dense follicle-like arrangement in association with a thickened, invaginated epithelium overlying its periphery, while the epithelium overlying the area of greatest infiltration was often thin or absent (Fig 4A), and absence of goblet cells. Underlying the leucocytic aggregate, the vascular endothelium was occasionally cuboidal, resembling HEVs of lymph nodes (Fig 4B). CD54 (ICAM-1) was heavily expressed on the endothelium of capillaries associated with aggregates of allografts (Fig 4C), to a lesser extent with isografts, but not on endothelium elsewhere in the conjunctiva. CD54 was expressed in the basal layers of the conjunctival epithelium (Fig 4C) and more strongly in the epithelium adjacent to the aggregates.

\section{Changes in conjunctival epithelium associated with lymphoid aggregates}

Three anti-cytokeratin antibodies ${ }^{2627}$ were used to characterise the epithelium associated with the aggregate, particularly whether the palisade-like cells observed on the surface (Fig 4D) were altered epithelial cells. This would confirm, firstly, the observed increase in the thickness of epithelium in the periphery of lymphoid aggregates and, secondly, absence of epithelium over the areas of greatest infiltration. No expression of either cytokeratin 4 (specific for parabasal and basal cells of non-keratinised stratified squamous epithelium) or 14 (non-keratinised stratified squamous epithelium) was observed. The pan-cytokeratin antibody confirmed these findings, except that there were a few scattered cells in the substance of the lymphoid aggregate (Fig 4D), which are likely to represent invaginated epithelium. The lack of MHC class I expression also supported the absence of epithelium (Fig 4E) above the leucocytic infiltration.

\section{Composition of infiltrating cells in conjunctiva after transplantation}

The infiltrate in areas outside the aggregate towards the limbus consisted predominantly of macrophages and MHC 
Table 3 Eyes examined for immunohistology and incidence of histologically identified leukocytic aggregates

\begin{tabular}{|c|c|c|c|c|}
\hline \multirow[b]{2}{*}{ Type of staining performed } & \multicolumn{2}{|l|}{ Day 10* } & \multicolumn{2}{|l|}{ Day 15} \\
\hline & Allograft & Isograft & Allograft & Isograft \\
\hline $\begin{array}{l}\text { Leucocytes, MHC, adhesion molecules } \\
\text { Cytokines } \\
\text { Cytokeratins, NK cells double stain cytokine/cell } \\
\text { phenotype }\end{array}$ & $\begin{array}{l}3 / 4 \dagger \\
1 / 3 \\
\text { Not done }\end{array}$ & $\left.\begin{array}{l}1 / 4 \\
0 / 2 \\
\text { Not done }\end{array}\right\}$ & $\begin{array}{l}1 / 4 \\
3 / 4\end{array}$ & $\begin{array}{l}1 / 4 \\
0 / 2\end{array}$ \\
\hline
\end{tabular}

class $\mathrm{II}^{+}$cells, and was more dense in the upper lid (Fig 4F). Aggregates were identified by histology in conjunctivas of $2 / 12$ isograft recipients (one on day 10 and one on day 15) and $8 / 15$ allograft recipients (four on day 10 and four on day 15).

All cell types were more abundant in aggregates associated with allografts compared to isografts (Fig 5). Within these aggregates, the cells exposed to the tear film were palisadelike (arrowheads in Fig 4D and G), whereas deeper cells were frequently arranged in a circular follicle-like pattern (Fig 4H). MHC class $\mathrm{II}^{+}$cells were predominant in the superficial areas-that is, area "a" in Fig 1 (Fig 6A), whereas in the stroma (area "b" in Fig 1), T cells (CD4 ${ }^{+}$, Fig 6B and CD8 $\alpha^{+}$, Fig 6D) were more numerous. There was a higher proportion of $\mathrm{T}$ cells relative to macrophages and granulocytes in the allografts in comparison with isograft associated aggregates (Fig 5A and B). CD4 ${ }^{+}$cells co-localised with CD25 (compare Figs $6 \mathrm{~B}$ and $\mathrm{C}$ ). $\mathrm{CD} 8 \alpha^{+}$cells were mainly in stroma and $\mathrm{ED} 2^{+}$ cells were arranged in the stroma in a circular pattern (Fig 4H). Granulocytes represented the majority cell infiltrate and were distributed randomly throughout (Fig 6E). There were a few B cells located in the deeper stromal areas. We estimated NK cells to comprise up to $10 \%$ of the cells in the lymphoid aggregate, located mainly in the stroma (Fig 4G).

\section{Cytokine expression}

Leucocytic aggregates were found in 4/11 conjunctivas examined for cytokine expression, all of which were allografts. In these aggregates, there was no detectable ILl $\beta$ despite consistent expression in positive control spleen derived from the same animals and processed simultaneously. IFN $\gamma$ and $\mathrm{TNF} \alpha$ were strongly expressed in all four aggregates. IFN $\gamma$ expression was focal, but present in both the superficial and deeper follicular areas (Fig 6F), whereas TNF $\alpha$ (Fig 6G) was in general more diffusely distributed. Double immunofluorescence staining revealed that $\mathrm{CD} 8 \alpha^{+}$and $\mathrm{ED} 2^{+}$cells expressed both IFN $\gamma$ and TNF $\alpha$ (Fig 6H, I, and J).

\section{DISCUSSION}

We were not able to demonstrate organised lymphoid aggregates in normal rat conjunctiva, confirming previous work. $^{20}$ The normal (unoperated) rat conjunctiva had a diffuse distribution of leucocytes, mostly macrophages, but also a few scattered MHC class $\mathrm{II}^{+}$dendritic cells, $\mathrm{CD}^{+}$and $\mathrm{CD}^{+} \mathrm{T}$ cells (both intraepithelially and within stroma) and granulocytes, resembling the resident leucocyte population in healthy human conjunctiva. ${ }^{28}{ }^{29}$ However, there were differences in that cells were less numerous compared to numbers in humans and there were no follicular aggregates containing B cells, as seen in humans. ${ }^{1421}$

The organised lymphoid tissue induced by transplantation was more pronounced in recipients of allografts than isografts, displayed the characteristic of a transient Thl response, and a structure that might facilitate antigen presentation across the ocular surface. Expression within the conjunctiva of IFN $\gamma$ and TNF $\alpha$ by $E D 2^{+}$macrophages and CD $8 \alpha^{+} \mathrm{T}$ cells supports classic activation of macrophages ${ }^{30} 31$ and $\mathrm{CD}^{+} \mathrm{T}$ cells and represents a strong pro-inflammatory milieu. Lymphoid hyperplasia has also been observed in the conjunctiva of rabbits during corneal allograft and xenograft rejection..$^{32}{ }^{33}$ It can be argued, at least in rats, that it conforms to a more traditional concept of CALT as a tissue associated with $\mathrm{T}$ cell immunity ${ }^{12}$ and lacking features considered to be definitive of organised MALT, such as B cell follicles or IgA production and the functional capacity to induce or promote tolerance.

Clinical signs of conjunctival changes were seen as early as 3 days post-transplantation, and were similar in isografts and allografts until day 6, implying that aggregate development was initiated by the non-specific injury of the surgery. The fact that there was equal operative trauma around the entire cornea but the aggregates always arose in the upper temporal palpebral conjunctiva, suggests that this location may be structurally predetermined. By the time rejection was under way (day 15), aggregate development was significantly
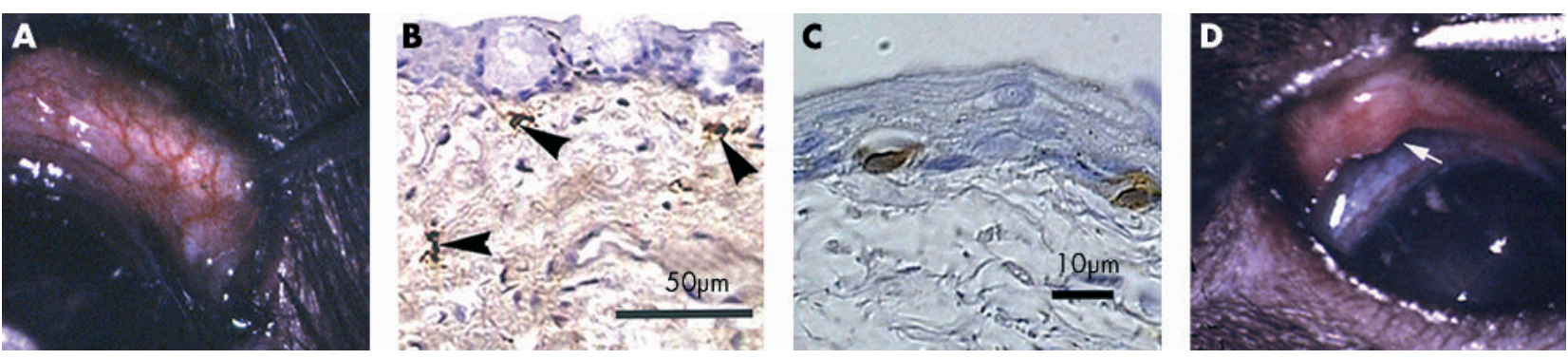

Figure 2 (A) Appearance of normal conjunctiva of the temporal half of the upper lid (lid everted with forceps) without clinically evident leucocytic aggregate. Note absence of oedema and normal vasculature (original magnification $\times 15$ ). (B) ED2 $2^{+}$macrophage (arrowheads) and (C) CD8 $\alpha^{+}$cells in normal conjunctiva. (D) Clinical appearance of aggregate on day 10 after transplantation showing hyperaemia, overhanging edge (arrow), and swelling, clinical score 4 (original magnification $\times 10$ ). 


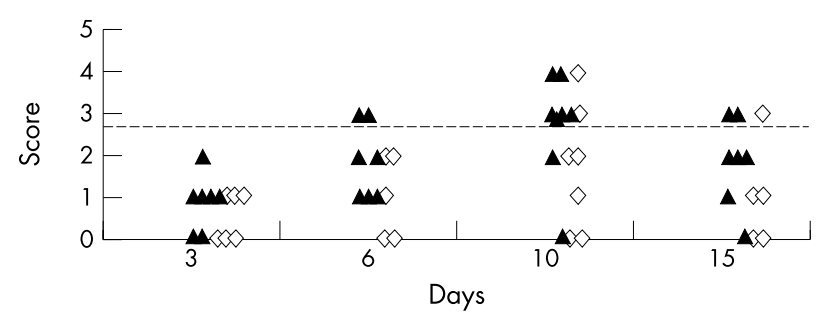

Figure 3 Clinical scores of conjunctiva in allografts $(\boldsymbol{\Lambda}, n=7)$ and isografts $(\diamond, n=6)$ before and during rejection. Broken line indicates score equivalent to histological identifiable lymphoid aggregate.

greater in allografts than in isografts. This, together with the greater cell infiltrate and numbers of activated cells in allograft associated aggregates, implies that maximal development was alloantigen dependent. Such a notion is further supported by similarities in the nature of the infiltrate in conjunctiva and allograft cornea, including a granulocyte infiltration and lack of $\mathrm{B}$ cells. Indicators of alloactivation included a higher proportion of T cells and CD25, CD2, CD18, and CD54 expressing cells in allograft associated aggregates, together with a Thl-like (IFN $\gamma$ and TNF $\alpha$ ) cytokine profile. Strong CD54 expression on vascular endothelium within the lymphoid aggregates and morphological changes in some blood vessels consistent with development of HEV ${ }^{34}{ }^{35}$ suggest that they are sites of extravasation and proliferation of T cells. The thinning and loss of epithelium and concentration of $\mathrm{CD}^{+}$and MHC class $\mathrm{II}^{+}$DCs at the surface of the aggregates, where they might gain access to antigen shed from the epithelium further support this. In the deeper areas, MHC class $\mathrm{II}^{+}$DCs were interspersed with $\mathrm{CD} 4^{+}, \mathrm{CD} 8^{+}$and $\mathrm{CD} 25^{+}$ cells, as would be expected in conditions of active antigen presentation and $\mathrm{T}$ cell proliferation. Concentration of $\mathrm{T}$ cells in a "trail" between the aggregates and the limbus is suggestive of $\mathrm{T}$ cell trafficking between this area and the cornea. Whether the aggregates are a site of antigen presentation to naive $\mathrm{T}$ cells or whether such presentation occurs only in regional draining lymph nodes remains
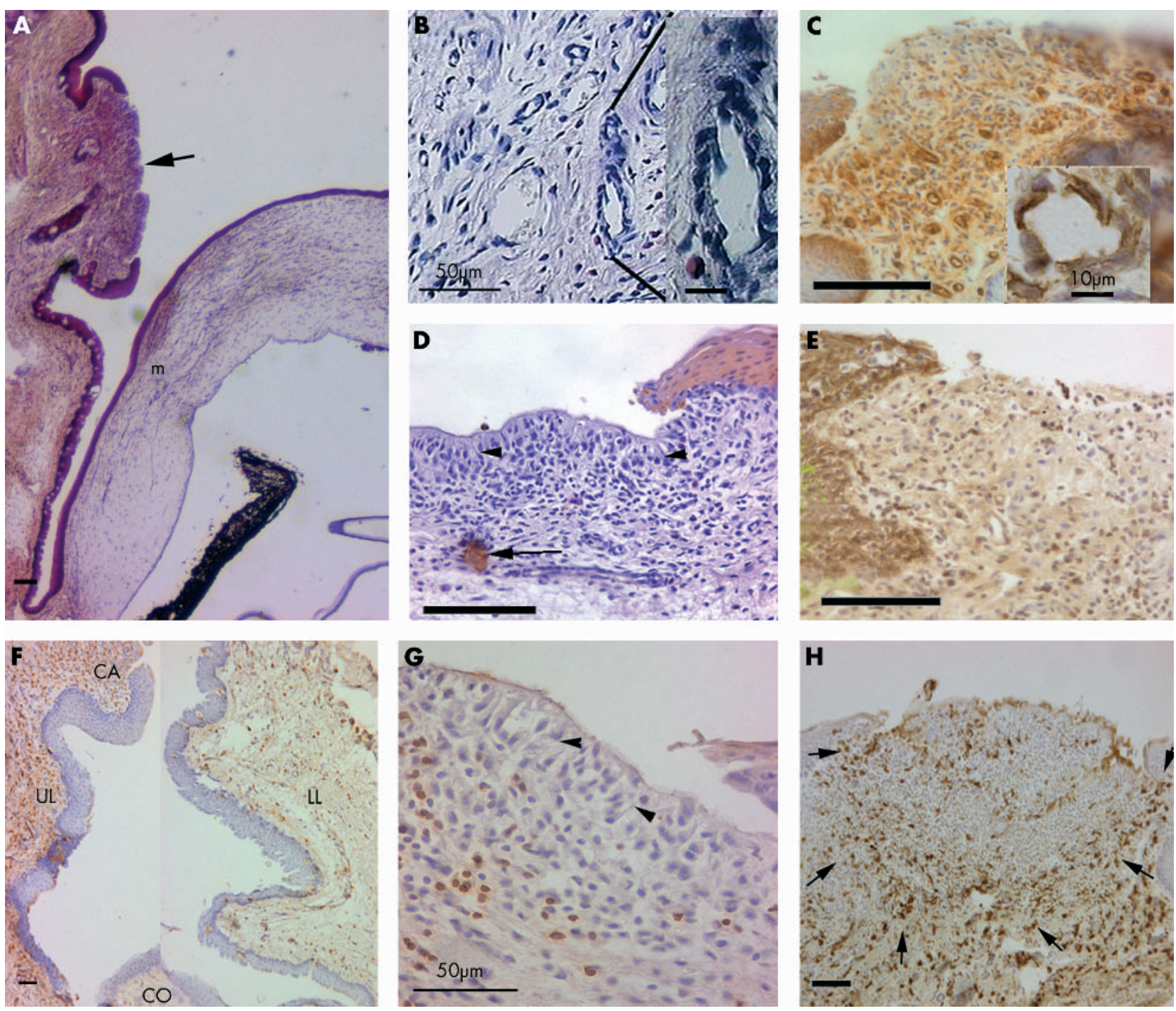

Figure 4 (A) Location of leucocytic aggregate (arrow) in the palpebral conjunctiva (haematoxylin and eosin). Note goblet cells are absent in adjacent epithelium. $m$ = graft margin. (B) Capillary displaying HEV morphology. (C) CD54 expression on basal epithelium, infiltrating cells, and capillary endothelium (inset). (D) Pancytokeratin staining showing lack of epithelium (note pallisading arrangement, arrowheads) overlying the aggregates but occasional cells (arrow) in the stroma. (E) MHC class I staining is not evident in superficial aggregate. (F) Composite picture showing CD4 $4^{+}$cells in upper (UL) and lower (LL) conjunctiva of the same section. Infiltration is more dense in UL, between the aggregates (CA) and the cornea (CO), than in LL. (G) NK cell are mainly in the stroma. Note pallisading (arrowheads) of cells in superficial layers. (H) ED2 $2^{+}$macrophages in circular arrangement in the aggregate defined by arrows. All unlabelled bars are $100 \mu \mathrm{m}$. 

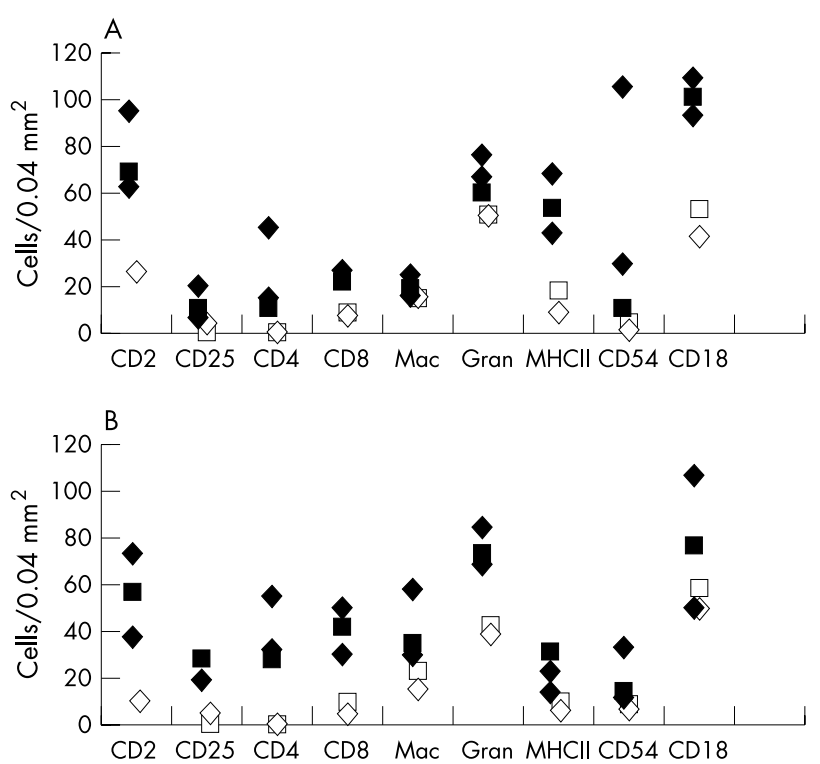

Figure 5 Cell numbers in (A) superficial (" $a$ " in Fig 1) and (B) stromal areas (" $b$ " in Fig 1) of five leucocytic aggregates large enough for all cell types to be identified. Closed symbols indicate allografts; open symbols = isografts; diamonds = day 10 ; squares = day 15 after transplantation. Note lower count of cells in isograft associated aggregates.
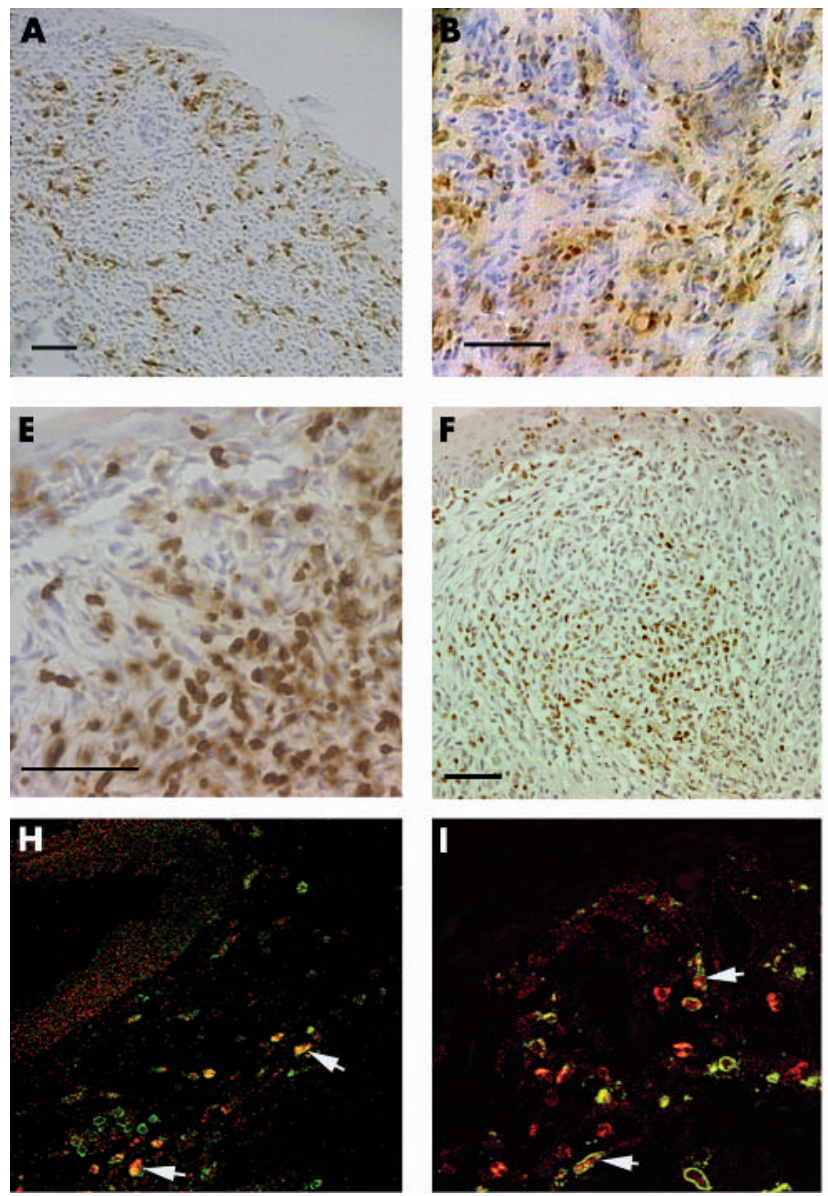

uncertain. Although both IFN $\gamma$ and TNF $\alpha$ were present in the aggregate, we could not detect IL- $1 \beta$ expression, which is central to activation and migration of DC from the site of antigen capture. ${ }^{36}$ However, such expression may not be necessary as late as day 10 after transplantation when many other activating signals are likely to be present.

Unlike the gut and respiratory mucosa, the conjunctiva is not primarily an absorptive surface and lacks the characteristic M cells of the single layered epithelium of GALT and BALT. ${ }^{10}$ The loss of epithelium we observed overlying aggregates occurred only at this site and may simply have been a pathological consequence of the large numbers of infiltrating cells. Alternatively, it may be a specific adaptation to facilitate rapid antigen uptake and $\mathrm{T}$ cell activation in appropriate conditions in a species in which the normal conjunctiva contains few lymphocytes and/or in a mucosa where the epithelium is normally stratified, bears tight junctions in the apical layers and, is relatively impermeable. ${ }^{187}$ It is reminiscent of reticulosis of tonsils during acute tonsillitis $^{38}$ and of the extreme thinning and loss of epithelial basement membrane observed in organised human CALT at the point of maximal leucocytic aggregation. ${ }^{13}{ }^{15}$ It is suggested that breakdown of epithelial basement membrane occurs in MALT in areas of leucocytic infiltration to facilitate antigen transport. ${ }^{39}$ It may be argued that the loss of epithelium is an artefact of tissue processing. However, we believe it not to be the case because we have seen progressive thinning of the epithelium in consecutive sections
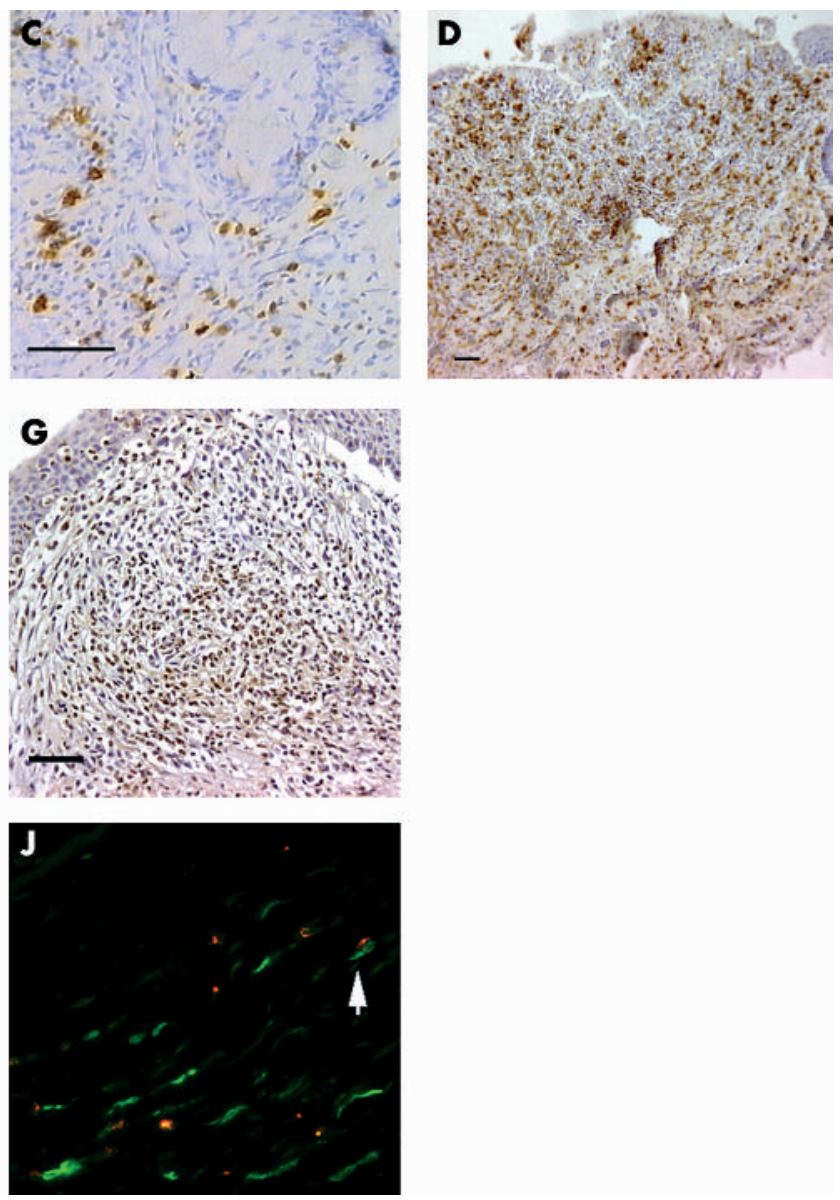

Figure 6 (A) MHC class II expressing cells are numerous in superficial leukocytic aggregates. (B) $C D 4^{+} T$ cells colocalise with (C) CD25 cells. (D) $\mathrm{CD} 8 \alpha$ staining is greater in stromal areas and expressed on round and dendritic cells. (E) Granulocytes in aggregates within both superficial and stromal areas. (F) IFN $\gamma$ expression and (G) TNF $\alpha$ expression in leucocytic aggregates. Immunofluorescence double staining showing cells (arrows) positive for (H) IFN $\gamma$ (red) and CD8 $\alpha$ (green) $(\times 20)$; (I) IFN $\gamma$ (red) and ED2 ${ }^{+}$macrophages (green) $(\times 40)$; (J) TNF $\alpha$ (red) and ED2 $2^{+}$macrophages (green) $(\times 40)$. Unlabelled bars are $50 \mu \mathrm{m}$. 
and in many instances (for example, Fig $4 \mathrm{~A}$ and $\mathrm{H}$ ) the aggregate protruded above the surface of the adjoining epithelium and contained unusual (palisade-like) cells at the surface.

The general lack of B cells in rat conjunctiva is consistent with the evidence reviewed by Sullivan ${ }^{22}$ that the conjunctiva is not a component of the secretory immune system-that is, a site of local B cell proliferation for IgA production, which is restricted to the lacrimal gland. However, a clear species difference between rat and humans appears to exist, because, $\mathrm{B}$ cells are found in conjunctival inflammatory conditions in humans ${ }^{40}$ and, indeed, in conjunctiva that is otherwise healthy. In one study, follicles containing B cells were identified in 21 out of 36 cadaver eyes. ${ }^{14}$ However, the incidence was lower (31\%) if only confirmed healthy individuals were considered. ${ }^{41}$

Although the features we describe here are not associated with induction of tolerance, there is evidence that specific tolerance can be induced by instillation of soluble antigen into the conjunctiva in mice and rats. ${ }^{16}{ }^{17}$ In view of the relative impermeability of the healthy conjunctiva, it is possible that this is achieved via the gut, by drainage of antigen through the lacrimal duct to the oral cavity.

The aggregates we observed resemble certain organised GALT structures composed mainly of T cells which develop after birth in response to antigenic load, ${ }^{42}$ and to CALT as traditionally described, containing mitotic lymphocytes, lymphatic channels and modified overlying epithelium. ${ }^{12}$ We cannot discount the possibility that they were initiated by mild microbial infection, although we emphasise that antibiotic ointment was regularly administered to the eye and there was no sign of endophthalmitis at any time. As we did not find aggregates in association with all allografts, they are clearly not essential for graft rejection or a major site of alloactivation. Comparable lymphoid hyperplasia in humans associated with rejection has not been reported, but in rabbits its development seems to reduce the success of immunosuppressive therapy. ${ }^{33}$ There have been no human studies to indicate whether the extent of pre-existing organised lymphoid tissue in the conjunctiva, irrespective of the original inflammatory stimulus, is a predisposing factor to graft rejection. Such a link is possible, particularly in view of the evidence that alloreactive $\mathrm{T}$ cells are of memory phenotype-that is, were primed during previous encounters with common environmental antigens, but cross react with antigens of the graft. ${ }^{43}$ Although the aggregates did not persist for long after a corneal transplant, in animals that developed them we observed the accelerated reappearance of the aggregate after a second transplant. This is evidence that even their transient development can have a bearing on later local immune responses. However, to test whether aggregates are a serious predisposing factor to rejection of a first transplant or to accelerate rejection of a subsequent transplant, further experiments using a strain combination in which rejection is less acute would be required.

\section{ACKNOWLEDGEMENTS}

This work was funded by a grant from the National Eye Research Centre.

We thank the Medical Research Council for providing an Infrastructure Award to establish the School of Medical Sciences Cell Imaging Facility and Dr Mark Jepson and Mr Alan Leard for their assistance.

\section{Authors' affiliations}

S Baneriee, D L Easty, A D Dick, S M Nicholls, Division of Ophthalmology, School of Medical Sciences, University Walk, Bristol BS8 1TD, UK
F C Figueiredo, Department of Ophthalmology, Royal Victoria Infirmary, Queen Victoria Road, Newcastle upon Tyne NEI 4LP, UK

\section{REFERENCES}

1 Strober W. Inductive and effector tissues and cells of the mucosal immune system. In: Ogra PL, Mestecky J, Lamm ME, et al, eds. Mucosal immunology, 2nd ed. San Diego: Academic, 1998:283-484.

2 Berg EL, McEvoy LM, Berlin C, et al. L-selectin-mediated lymphocyte rolling on MAdCAM-1. Nature 1993;366:695-8.

3 Tomasi TB Jr, Tan EM, Solomon A, et al. Characteristics of an immune system common to certain external secreations. J Exp Med 1965;121:101-24.

4 Tomasi TB Jr. Oral tolerance. Transplantation 1980;29:353-6.

5 Inobe Jl, Chen Y, Weiner HL. In vivo administration of IL-4 induces TGF-betaproducing cells and protects animals from experimental autoimmune encephalomyelitis. Ann N Y Acad Sci 1996;778:390-2.

6 Chen Y, Inobe J, Marks R, et al. Peripheral deletion of antigen-reactive T cells in oral tolerance. Nature 1995;376:177-80.

7 Daynes RA, Araneo BA, Dowell TA, et al. Regulation of murine lymphokine production in vivo. III.The lymphoid tissue microenvironment exerts regulatory influences over T helper cell function. J Exp Med 1990;171:979-96.

8 Neutra MR, Frey A, Kraehenbuhl JP. Epithelial M cells: gateways for mucosal infection and immunization. Cell 1996;86:345-8.

9 Bienenstock J, McDermott $M$, Befus $D$, et al. A common mucosal immunologic system involving the bronchus, breast and bowel. Adv Exp Med Biol 1978;107:53-9.

10 Gebert A, Pabst R. M cells at locations outside the gut. Sem Immunol 1999;11:165-70.

11 Neutra MR, Pringault E, Kraehenbuhl JP. Antigen sampling across epithelial barriers and induction of mucosal immune responses. Annu Rev Immunol $1996 ; 14: 275-300$.

12 Chandler JW, Gillette TE. Immunologic defense mechanisms of the ocular surface. Ophthalmology 1983;90:585-91.

13 Franklin RM, Remus LE. Conjunctival-associated lymphoid tissue: evidence for a role in the secretory immune system. Invest Ophthalmol Vis Sci 1984;25:181-7.

14 Knop N, Knop E. Conjunctiva-associated lymphoid tissue in the human eye. Invest Ophthalmol Vis Sci 2000;41:1270-9.

15 Chodosh J, Nordquist RE, Kennedy RC. Comparative anatomy of mammalian conjunctival lymphoid tissue: a putative mucosal immune site. Dev Comp Immunol 1998;22:621-30.

16 Egan RM, Yorkey C, Black R, et al. In vivo behavior of peptide-specific T cells during mucosal tolerance induction: antigen introduced through the mucosa of the conjunctiva elicits prolonged antigen-specific T cell priming followed by anergy. J Immunol 2000;164:4543-50.

17 Dua HS, Donoso LA, Laibson PR. Conjunctival instillation of retinal antigens induces tolerance. Does it invoke mucosal tolerance mediated via conjunctival associated lymphoid tissue (CALT)? Ocular Immunol Inflam 1994;2:29-36.

18 Stock EL, Sobut RA, Roth SI. The uptake of horseradish peroxidase by the conjunctival epithelium of the guinea-pig. Exp Eye Res 1987:45:327-37.

19 Fujihashi K, Dohi T, Rennert PD, et al. Peyer's patches are required for oral tolerance to proteins. Proc Natl Acad Sci USA 2001;98:3310-5.

20 Gomes JA, Jindal VK, Gormley PD, et al. Phenotypic analysis of resident lymphoid cells in the conjunctiva and adnexal tissues of rat. Exp Eye Res 1997:64:991-7.

21 Hardman-Lea S, Kerr-Muir M, Wotherspoon AC, et al. Mucosal-associated lymphoid tissue lymphoma of the conjunctiva. Arch Ophthalmol 1994;112:1207-12.

22 Sullivan DA. Ocular mucosal immunity. In: Ogra PL, Mestecky J, Lamm ME, et al, eds. Mucosal immunology, 2nd ed. San Diego: Academic Press, 1998:1241-81.

23 Figueiredo FC, Pendergrast DG, Zhang L, et al. An improved method for examining the corneal endothelium during graft rejection in the rat. Exp Eye Res 1998;67:625-30.

24 Whiteland JL, Nicholls SM, Shimeld C, et al. Immunohistochemical detection of T-cell subsets and other leukocytes in paraffin-embedded rat and mouse tissues with monoclonal antibodies. J Histochem Cytochem 1995:43:313-20.

25 Whiteland JL, Shimeld C, Nicholls SM, et al. Immunohistochemical detection of cytokines in paraffin-embedded mouse tissues. J Immunol Methods 1997;210:103-8

26 Schlage WK, Bulles $\mathrm{H}$, Friedrichs $\mathrm{D}$, et al. Cytokeratin expression patterns in the rat respiratory tract as markers of epithelial differentiation in inhalation toxicology. II. Changes in cytokeratin expression patterns following 8-day exposure to room-aged cigarette sidestream smoke. Toxicol Pathol 1998;26:344-60.

27 Kasper M. Heterogeneity in the immunolocalization of cytokeratin specific monoclonal antibodies in the rat eye: evaluation of unusual epithelial tissue entities. Histochemistry 1991;95:613-20.

28 Hingorani M, Metz D, Lightman SL. Characterisation of the normal coniunctival leukocyte population. Exp Eye Res 1997:64:905-12.

29 Dua HS, Gomes JA, Jindal VK, et al. Mucosa specific lymphocytes in the human conjunctiva, corneoscleral limbus and lacrimal gland. Curr Eye Res 1994;13:87-93.

30 Schultz RM, Kleinschmidt WJ. Functional identity between murine gamma interferon and macrophage activating factor. Nature 1983;305:239-40

31 Nathan CF, Murray HW, Wiebe ME, et al. Identification of interferon-gamma as the lymphokine that activates human macrophage oxidative metabolism and antimicrobial activity. J Exp Med 1983;158:670-89. 
32 Polack FM. The pathologic anatomy of corneal graft rejection. Surv Ophthalmol 1966;11:391-404.

33 Polack FM. Effect of azathioprine (imuran) on corneal graft reaction. Am J Ophthalmol 1967:64:233-44.

34 Knop E, Knop N. Lacrimal drainage-associated lymphoid tissue (LDALT): a part of the human mucosal immune system. Invest Ophthalmol Vis $S_{c i}$ 2001;42:566-74.

35 Dua HS, McKinnon A, McMenamin PG, et al. Ultrastructural pathology of the 'barrier sites' in experimental autoimmune uveitis and experimental autoimmune pinealitis. Br J Ophthalmol 1991;75:391-7.

36 Banchereau J, Steinman RM. Dendritic cells and the control of immunity. Nature 1998;392:245-52.

37 Huang AJ, Tseng SC, Kenyon KR. Paracellular permeability of corneal and conjunctival epithelia. Invest Ophthalmol Vis Sci 1989;30:684-9.
38 Salles MW, Middleton DM. Lymphocyte subsets in porcine tonsillar crypt epithelium. Vet Immunol Immunopathol 2000;77:133-44

39 Ruco LP, Uccini S, Stoppacciaro A, et al. The lymphoepithelial organization of the tonsil: an immunohistochemical study in chronic recurrent tonsillitis. J Pathol 1995; 176:391-8.

40 Foster CS, Rice BA, Dutt JE. Immunopathology of atopic keratoconjunctivitis. Ophthalmology 1991;98:1190-6.

41 Wotherspoon AC, Hardman-Lea S, Isaacson PG. Mucosa-associated lymphoid tissue (MALT) in the human conjunctiva. J Pathol 1994;174:33-7.

42 Moghaddami M, Cummins A, Mayrhofer G. Lymphocyte-filled villi: comparison with other lymphoid aggregations in the mucosa of the human small intestine. Gastroenterology 1998;115:1414-25.

43 Rotzschke O, Falk K, Faath S, et al. On the nature of peptides involved in T cell alloreactivity. J Exp Med 1991;174:1059-71. 